\title{
Tweeting, friending, reporting Social media use among journalism academics, students and graduates in the Asia-Pacific
}

\begin{abstract}
This reflective article describes and analyses the use of Facebook and Twitter over a five-year timeframe by two journalism academics in Australia, whose industry and research expertise are in the Asia-Pacific. The use of social media has made possible for journalism educators an active electronic space in which to conduct discourse on development, publication, networking and career opportunities with students and alumni. This discourse and the educators, students or alumni who engage in it reflect the nature of the global media industry as inherently network-based (in contrast to employment approaches found in other industries such as graduate programmes in commerce, law or engineering). Because it operates using electronic communication, such discourse also reflects the industry which journalism graduates seek to enter as not being geographically confined to one city or state within Australia-instead, reflecting a rapid rate of movement between cities and states, or between countries, or between urban and rural locations. Using active participant observation, the researchers argue that social media can be used to develop and retain links with their students and alumni, by making use of the social connectedness that is coming to characterise communication. The researchers were early adopters of Facebook and Twitter communication with students. The article argues that social media has been beneficial in the conduct of these activities while exploring the use of social networking in relation to the politics of 'friending' or 'following' and 'being followed' by students.
\end{abstract}

Keywords: Australia, journalism academics, journalism education, media, social media

NASYA BAHFEN

Monash University, Melbourne

\section{ALEX WAKE \\ RMIT, Melbourne}

I don't tend to poke students any more- but I have every intention of continuing to poke a graduate from three years ago who should have got a job by now instead of swanning around the world-One of the authors of this article, on her research blog

ANY academics argue that they shouldn't friend students on Facebook. But as journalism educators we believe that we have an obligation to not only approve students' friend requests on Facebook, but to also follow students (on 
Twitter), because we see these practices as beneficial for the students' development and professionalism. We argue that they make journalism educators better at teaching, and allow journalism educators to connect students and former students with opportunities in their chosen field.

This reflective article describes, analyses and justifies our use of Facebook and Twitter in our work from 2007 to 2012 as two journalism academics in Australia, whose industry and research expertise are in the Asia-Pacific. The use of social media has made possible for us as journalism educators to engage in an active electronic space which we use to conduct discourse on development, publication, networking and career opportunities with students and alumni. Our premise is that such a discourse and the educators, students or alumni who engage in it reflect the nature of the global media industry as inherently network-based (in contrast to employment approaches found in other industries such as graduate programs in commerce, law or engineering). Because it operates using electronic communication, such discourse also reflects the industry which our graduates seek to enter as not being geographically confined to one city or state within Australia - instead, reflecting a rapid rate of movement in media jobs across the Asia-Pacific region and beyond, between cities and states, or between countries, or between urban and rural locations.

Using active participant observation and an ethnographic approach, we try to build a case that social media can be used to develop and retain links with students and alumni, by making use of the social connectedness that is coming to characterise communication. We were early adopters of Facebook and Twitter communication with students, telling university administrators who warned against such interactions on social media that students who plan to work in journalism must learn to engage with it in a professional manner. This article draws heavily on our personal experiences to discuss the use of social media as a way of networking, sharing employment or publication opportunities, and providing advice after students graduate. Our article argues that social media has been beneficial in the conduct of these activities while acknowledging the concerns fellow educators have encountered or observed in relation to the politics of 'friending' or 'following' and 'being followed' by students on social media.

\section{Social media and higher education}

The subject of social media use by journalism educators in the course of teaching future journalists has not been subject to extensive research, although there is a growing body of work on the way that social media has had an impact on journalism practice. The intersection of social media and journalism constitutes nothing less than a paradigm shift in the media industry, according to Ludtke (2009) in that journalism has changed from a lecture to a conversation. Newsrooms have reacted in different ways to the adaptation of new technologies (Boczkowski, 2004). While many journalists were immediately aware of how social media enabled improved communication between newsrooms and the 
public, others were cautious about adopting such tools given the challenges involved, such as the accuracy of information shared on social media.

Rather than playing the role of the Fourth Estate in monitoring government and holding those in power accountable (Gentzkow, Glaeser, \& Goldin 2006), as media adopts new technologies it is forced to negotiate and incorporate the principle of talking and sharing associated with the internet, and in the process make the adaptation of social media a duty incumbent on journalists (Ludtke 2009). There are parallels in our envisioning of social media as a form of participatory publishing with the work of Nguyen (2009), who believes journalism educators need to embrace (both theoretically and practically) social media use because of predicted changes in the role of the profession they are preparing their students for, from a gatekeeper of content to a listener, facilitator and participant of conversations.

In our journalism practice we have witnessed the increasing role played by social media in the creation and consumption of news. Reflecting on this increased role, Stassen (2010) states that journalists have an obligation to engage with audiences, who are electronically connected to media outlets to an extent never seen before. This engagement can take the form of adoption of new methods of delivery for stories, as well as building communities around content on Twitter, YouTube and Facebook (Stassen 2010). According to Newman (2009), major global stories are indicative of how social media has changed journalism practice, in particular the street protests against the G20 summit held in London and the contested Iranian elections, both of which took place in 2009. Twitter and Facebook became sites where Iranian activists and those following the elections gathered to disseminate and discuss information which Iranian authorities attempted to control through television and radio. Because of the harassment faced by international correspondents including restrictions on movement and deportation, the content posted by citizen journalists became an integral part of the Iranian election narrative, even when mainstream and professional media outlets were unable to verify the photos and footage (Newman, 2009).

In terms of the impact on the work of a journalist, the competent use of social media is now a skill that is integral to many journalism roles, which call for reporters to be producers of content across platforms instead of being tied to a particular platform such as radio, television, or print (Beam \& Meeks 2011; Hirst \& Treadwell, 2011). As professional journalists, we have been required to fulfill the pressing need of producing stories for various online formats, despite our print and radio-focused backgrounds. Recently, BBC staff were not merely encouraged to use social media, but instead forced to, with the British public broadcaster's management taking the position that using social media is part and parcel of being an effective staff member in a media organisation (Qualman, 2012). The topic of social media usage in the day-to-day work of media professionals is one that has also been explored through the lens of public relations, in relation to how 
practitioners in that industry connect with producers and journalists (Waters, Tindall $\&$ Morton 2011). In 2009 the use of social media as an information source by business journalists was not as widespread as the use of 'static' sources such as websites or online directories, although public relations practitioners were urged to prepare for a time when social media played a larger role in the news cycle (Lariscy et al., 2009).

The omnipresence of social media in today's newsrooms has implications for the teaching of journalism. As Bor (2014, p. 243) notes, 'It is not enough for graduates of journalism school to possess oral and written communication skills. They must also be effective in using an array of web-based platforms such as social media sites to report news'. We found that integrating social media into journalism curricula posed challenges for us as educators. Such challenges are also elaborated on at length by academics at AUT University, who found their journalism students to be technically savvy but unaware of how to use social media professionally or to create news-like content through blogs or YouTube, instead using social media sites in a predominantly personal capacity (Hirst \& Treadwell, 2011). Looking specifically at the use of social media in journalism education, they outlined their goal of making the journalism curriculum at AUT reflective of the changes in journalism practice brought about by the use of social media. They note that where technologically-driven changes take place in journalism and in the journalism job market, journalism education quickly adapts even if the question of how to integrate social media into the curriculum is a vexed one for journalism educators. Social media-driven changes in news production are not cosmetic or restricted to basic journalism practice (sourcing talent, for example) but also affect audience engagement with news, therefore, 'the industry and the academy cannot be blind to these trends' (Hirst \& Treadwell, 2011, p. 447). Diekerhof (2013) also warns against assuming that the youth of journalism students means they are digital natives in a professional sense; while they may be technologically savvy, their comfort with new technology does not automatically equate to an ability to put social media to use in conjunction with key journalism skills such as news gathering and telling a story. Empirical evidence exists to support these assertions by Hirst Treadwell (2011) and Diekerhof (2013). A study of three undergraduate broadcast journalism subjects at a United States university found that the integration of social media in assignments made students aware of the potential of social media use for career development, but also that students faced some difficulty in understanding the personal versus professional or journalistic use of social media (Bor, 2014).

The social group that is the focus of this paper consists of journalism students, alumni and educators from Melbourne's RMIT University from 2007-2012. RMIT offers longestablished journalism programmes at undergraduate or Bachelor and postgraduate by coursework Masters level. Its undergraduate programme sees more than 1300 applications annually for forty publicly funded places (Crikey, 2009). We were the journalism educators within the group - one is of Indonesian background and helped set up Melbourne's first Indigenous radio station before working for an Australian public broadcaster specifically

176 PACIFIC JOURNALISM REVIEW 21(1) 2015 
committed to multicultural broadcasting, and for a news station in Singapore where she also taught journalism. She then lectured at a Melbourne university with a predominantly international student cohort prior to joining RMIT in 2006 (and leaving in 2012). Her doctorate looked at internet usage among Muslim communities in Australia and Southeast Asia. The second journalism educator taught journalism in two Australian universities and spent three years teaching Arab women in the United Arab Emirates. She also worked for more than 20 years as a journalist or journalism educator in Ireland and South Africa and is completing a dctorate looking at journalism education conducted by Australians and New Zealanders. During the time frame examined by this study, we maintained our industry practice at the international radio division of Australia's main public broadcaster, covering stories on the Asia-Pacific region.

One of the criticisms of participant observation as a research method is the external status of the researcher as an outsider to the social group and context being studied-a status which can limit the breadth and depth of the data which is able to be collected (Johnson Avenarius \& Weatherford, 2006). In order to overcome this, we are using an active participant methodology where we are a part of the group that is the focus of the study. Our analysis draws on our experiences in the use of social media with local and international students and alumni from both journalism programmes at RMIT. It takes an ethnographic approach to the analysis and uses active participant observation as a reflective methodology. There are some key benefits of taking such an ethnographic approach to research involving a defined social group. Ethnographic research looks at the behaviour of group members within a natural environment instead of a constructed one (offering more scope for data that is richer in authenticity), as well as allowing the researcher to step into the shoes of the members of the group being studied - seeing things from their perspective and learning the 'language' used to communicate by the group (Elliott \& Jankel-Elliott, 2003).

\section{Social media and journalism education caveats}

Although social media interaction between students and educators can be described as an emerging area of study, research has already established concerns over the use by academics of such sites. For example, Hewitt and Forte (2006) found that of the 176 US-based tertiary students they surveyed over two years, two thirds were comfortable with academics being on Facebook, but the remainder cited various concerns including students' privacy and a belief that the relationship between students and educators should remain professional, instead of social (which it was perceived to be as a result of interaction on Facebook). The privacy of educators, on the other hand, was an issue identified by Mazer et al (2007) who found that an educators' credibility in the eyes of students could be affected by what she or he posted on Facebook.

In terms of using social media as a reporting tool, we acknowledge and are aware of a few limitations. Social media reaction has become de rigeur in reporting (particularly of 
lifestyle, celebrity, or sports news) and is viewed by media organisations as a convenient and quick way to interact with audiences and gauge public reaction to events (Stassen, 2010). However, it is rarely the primary reason for a news story, although we will teach students about those exceptions where social media is in fact the key point of the story, including the use of social media as a campaign strategy in the US elections of 2012, or cases of Facebook-advertised birthday parties which turned into riots when thousands of people turned up. A subsequent example that has arisen following the timeframe in which we conducted this reflection is the case of the communications professional whose racially insensitive Tweet cost her a job (Bercovici, 2013), which we would argue teaches journalism students two things - how a genuine story based on classic news values that is about social media might look like, and how important it is not to make such remarks on your Twitter feed or your Facebook timeline. We are also aware (through both research and our own professional practice) that there is a trade-off that Twitter in particular seems to make when it comes to speed for the cornerstones of journalism - accuracy and objectivity. Although Twitter is instantaneous, when social media is relied on as a news source, errors are amplified through re-tweeting, and again a primary example has since arisen following the timeframe covered by this paper in the case of the wrongly identified suspect in the Boston marathon bombings (Shih, 2013). We also teach students that social media often tests the journalistic aim of objectivity through the selection of some viewpoints to the detriment of others. For example, in the Iranian election of 2009, news narratives about the use of social media tended to favour the viewpoints of younger and more technically savvy Iranians, who were supportive of the opposition candidate (Newman, 2009).

In terms of using social media to build a community of graduates and current students for networking and distributing intra-group publishing, paid and volunteer opportunities, we have identified some cultural issues which pertain to our experiences as educators outside of Australia, and in societies that are starkly different to our own. We use Facebook to keep in touch with former students from the different parts of the world where we have taught including the United Arab Emirates and Singapore, and we are conscious of the different attitudes our Asian, Middle Eastern, European and Australian students have to things such as nudity, partying and drinking. While neither of us has ever defriended a student or former student, we have deleted some of their posts on our page, because some of our former students come from cultures where the behavior of young Australians can be confronting (and conversely for an Australian student, some of the viewpoints or photos that our international students post can be confronting). We ask all our students to consider how someone from a different society might react before they post things on our walls.

\section{Towards professional social media practice}

We are aware of and acknowledge the privacy, journalistic, and cultural concerns that come with the use of social media in journalism education but we are also aware of the

178 PACIFIC JOURNALISM REVIEW 21(1) 2015 
increased use of Facebook and Twitter as part of industry practice, given our work as professional journalists. So we approached our use of Facebook and Twitter as journalists, educators and human beings, from the position that the use of these two social media sites would quickly end up as a norm for groups of journalism students and educators. Over a timeframe of five to six years, we discovered it was useful to define three overall ground rules from the beginning (such as the first class of a semester) that would cover our collective use of Facebook and Twitter with the students.

1. Neither of us initiates friendship with students on Facebook although we will accept friend requests, but we will often follow students on Twitter. In both instances, this is dependent on the student being identifiable (using his or her name, a photograph or mutual friends or followers - who are often other students). We approach Twitter differently because fewer students use it, and we introduce it by explaining the benefits we found as practising journalists of following other journalists on Twitter whose work we admired, and pointing to concrete examples of recent students or younger journalists using Twitter to line up interviews or source background. We will often encourage a new cohort of students to sign up to Twitter, and then follow those students to get them started, and we have discussed in class journalists and newsmakers in different fields whose accounts are worth following. We differ in our views on whether students should put us on limited access on Facebook and in the end we feel that is a matter for them to decide.

2. We warn them that we use social media in a personal as well as a professional sense, but that we try to adhere to the basics of never disrespecting our partners, colleagues or universities on Facebook or Twitter, and that as tempting as it is to mouth off on social media, social media isn't the place for that. Nevertheless we let them know that we do often use social media, especially Facebook, to post personal or family related content, and that we have mad families, as they probably do too. Some evidence exists to suggest students who see educators sending only social or personal tweets viewed them positively in terms of the educators' credibility (Johnson, 2011). We send such personal and social tweets well as professional ones (in our case, news and current affairs related tweets), and on Facebook share photos of our families and friends because it is good for students to know that they are not the only ones who are important in our lives - and at times they will have to wait for assignment feedback because we have, for example, sick children. We also post news articles, journals and musings, which we think they will find interesting. Most of our Tweets or Facebook statuses relate to journalism, some relate to our fields of academic research or other interests, or some are just funny. We sometimes talk about students collectively but not to ridicule or to shame them-generally we 
mention them because they have done something great. Often we link to their journalism work, or congratulate a student or graduate when she or he gets a new position, or advertise (at the request of the former student concerned) a journalism role when a graduate moves on to another position.

3. We respond to assessment-related confusion or questions on social media, but not complaints. If students ask each other about assignments that we have set or are marking and we see that, we will often jump in to answer. If the question is a complaint or a grumble about an assignment we tend to ignore it. In class we often state that complaints about assignments should be communicated through the student's university email account to our staff email accounts. If we see a comment on Facebook or Twitter disrespecting a fellow student, a colleague or a working journalist (and one of us has only seen this twice, the other only once), we privately communicate our concern. On the occasions we have done this, students have removed the comment and thanked us for pointing out the dangers of saying things on social media which may come back to haunt them professionally.

With both of us having spent a considerable amount of time as broadcast journalists, we see social media as a kind of broadcasting - so we tell our students that they will not see us publicly drinking, smoking, lying, complaining about colleagues, or doing anything that reflects badly on our professionalism. But what they will see are ways where the use of social media intersects with journalism practice. As discussed by Diekerhof (2013) our students may be digital natives, but in order to explain to students in concrete terms about the benefits of professional use of social media and its use in journalism practice, we urge them to consider the following.

1. The use of a standard email address (firstname.lastname or a variation of this) that is kept only for job-related purposes (applying for internships, making pitches for freelance work, or registering for professional development opportunities).

2. The use of online file storage (we explain that we use Gmail so as to be able to connect with Google Drive, but students could equally use Dropbox or another online storage facility) to keep contact lists, rundowns for community radio and television shows they might be volunteering on, story ideas, and so on. We show them screenshots of our own contact lists with telephone numbers and email addresses blacked out, and explain that from experience, they may well end up juggling different casual jobs initially on graduation and therefore need quick access to their contact lists at different newsrooms.

3. The art of turning the bio for their Twitter account into a resumé, and following the accounts of journalists and relevant organisations in the field they are attempting to enter. We show them screenshots of recent graduates' Twitter

180 PACIFIC JOURNALISM REVIEW 21(1) 2015 


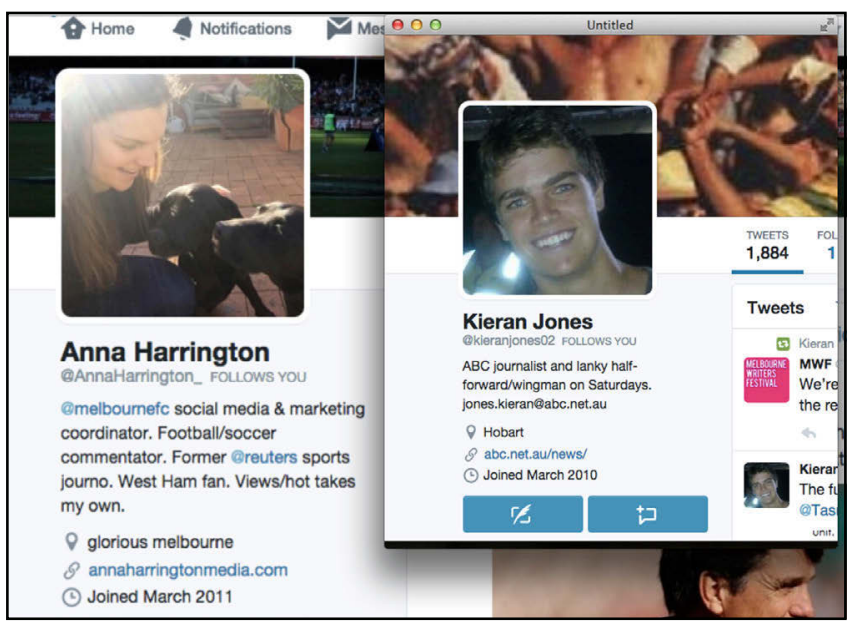

Figure 1: Recent Australian graduates' Twitter biographies.

biographies, which we view as exemplars (see Figure 1) in that they demonstrate where a graduate is working, a link to their online portfolio, and something personal that shows a human side to the graduate/ Twitter account holder.

Because of our emphasis on, and experiences teaching, journalism as a cross-border industry, we are careful to include a range of such examples reflecting different countries and cultures including that of

a Malaysian former journalism student who had worked at the Australia Broadcasting Corporation's Asia-Pacific desk (see Figure 2).

4. The joining of key Facebook groups such as the one we set up for students about to graduate and recent graduates, where jobs and publishing opportunities are often posted, and the use of Facebook to crowd-source talent or interviewees for human interest and soft news stories (or hard news stories, using postings to groups or pages).

Historically, Australian journalism has been an industry where 'getting your foot in the door' involved building up experience and networking, with work placements and contacts a key factor in getting journalism-related roles (O'Donnell, 1999). One of the key benefits of using social media to interact with students is the ability for us as educators to continue to stay in touch with students once they graduate, enter the workforce, and often provide mentoring and career opportunities for the students who have come after them. Against this background where networking is critical to securing work, we are training students to be journalists in a highly public online world, where everything celebrities do and say is taken and

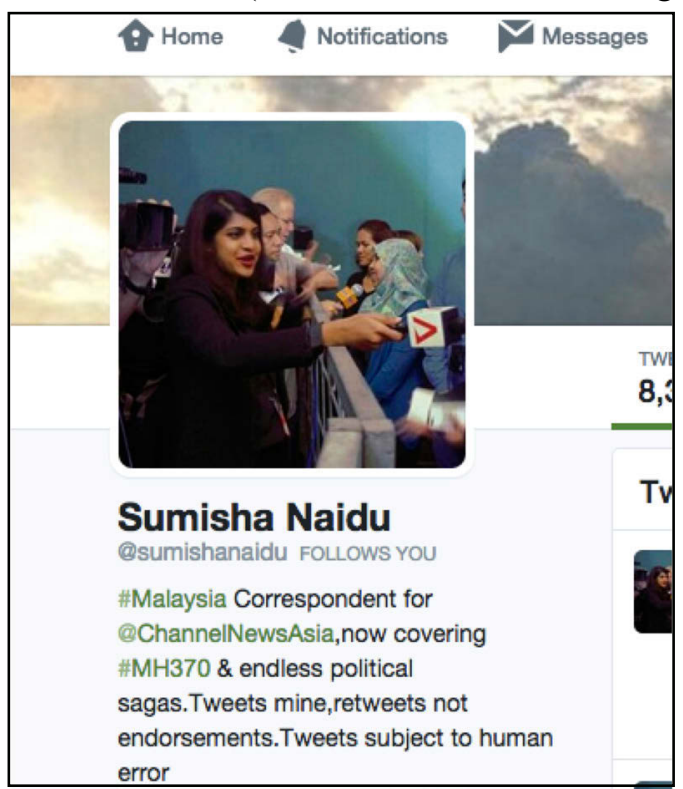

Figure 2: A recent international graduate's Twitter biography 
used against them in the media. One of the most important things for us to do as journalism educators is to prepare our students for that same kind of scrutiny. As educators, we do this in a classroom environment but by having us as Facebook friends or by following us on Twitter, we can act as reminders not to post something that could later come back to haunt them, while we teach them what we have found works from our journalism practice, and that of previous journalism graduates. Facebook and Twitter let us know where our students have gone, letting us keep in touch with them, which in turn means we are able to link current students to past ones.

\section{Conclusion}

At the World Journalism Educators Conference in South Africa in July 2011, one of the authors of this paper had lunch with four journalism educators who specialised in digital news. When the topic of social media use came up, one of the journalism educators made a strong case that we should allow students their own private space. Others believed that journalism educators should be active in the Facebook and Twitter world, but do so through means where the private and personal is clearly separated. While understanding these concerns, we disagree. Our disagreement stems from both the benefits that we have witnessed from engaging with our journalism students on social media and the grounding in theory of this engagement, which we are aware of. The subject of social media use specifically by journalism educators in the course of teaching future journalists has not been subject to extensive pedagogical research, although there is a growing body of work on the way that social media has had an impact on journalism practice through interaction with audiences and providing new sources of content and reaction or response from interviewees. Our industry and research experience covers the Asia-Pacific and in our journalism practice we have witnessed the increasing role played by social media in the creation and consumption of global news. As active participant observers and early adopters of Facebook and Twitter communication with journalism students, we have come to the conclusion that social media can be used to develop and retain links with journalism students and alumni. We acknowledge that there are concerns with the use of social media among students and educators, including issues of privacy, the credibility of the educator being compromised through social media use, and a belief that the relationship between students and educators should remain academic and professional without veering into the social or personal. There are also concerns over the use of social media in journalism practice such as the trading of speed for accuracy and objectivity, and the danger of relying on social media as the primary reason for a news story, although we acknowledge that sometimes this is the case. Finally, given our experiences as journalists and educators in the Asia-Pacific region we acknowledge the fact that there are cultural differences among our social media circles, and that if we are connected to our students and former students on Facebook and Twitter they need to be aware of those differences.

182 PACIFIC JOURNALISM REVIEW 21(1) 2015 
However, our journalism practice has led us to believe that students who plan to work in journalism must learn to engage with social media in a professional manner. Drawing on our personal experiences, we discussed the use of social media as a way of networking, sharing employment or publication opportunities, and providing advice after journalism students graduate. In this article we have argued that despite the concerns, our use of social media has been beneficial in the conduct of these activities while acknowledging the pitfalls that other researchers have identified, in relation to the politics of 'Facebook friending' or 'following' and 'being followed by' students on Twitter. In our use of Facebook and Twitter over a five-year timeframe we have identified some basic ground rules governing our interaction with students on social media, including differences in how we initiate or respond to social media contact (passively on Facebook by accepting friend requests and actively on Twitter by following students who are new to the site, and always dependent on being able to identify the student), using social media personally as well as professionally but never disrespecting our universities or the people we are connected to, and 'nipping in the bud' confusion about assessment that may be aired by students on social media while sticking to email to respond to complaints about assessment.

Actively engaging in social media with our journalism students and graduates is a reflection of the nature of today's media industry. We know that our students are likely to change jobs, or to move out of journalism altogether, and to move from cities to country locations or to move across countries. We know that they often obtain jobs through contact with alumni and graduates. Our industry and the industry we are preparing the students for is global, digital, and network based, and the competent and professional use of social media is a skill without which future journalists would be disadvantaged.

\section{References}

Beam, R., \& Meeks, L. (2011). 'So many stories, so little time': the changing professional environment. In W. Lowery \& P. Gade (Eds.), Changing the news: The forces shaping journalism in uncertain times (pp. 230-248). New York: Routledge.

Bercovici, J. (2013, December). Justine Sacco and the self-inflicted perils of Twitter. Forbes. Retrieved December 14, 2013 from www.forbes.com/sites/jeffbercovici/2013/12/23/justinesacco-and-the-self-inflicted-perils-of-twitter/

Boczkowski, P. J. (2004). The processes of adopting multimedia and interactivity in three online newsrooms. Journal of Communication, 54(2), 197-213.

Bor, S. E. (2014). Teaching social media journalism: Challenges and opportunities for future curriculum design. Journalism \& Mass Communication Educator, 69(3), 243-255.

Crikey. (2009, November). All those journalism graduates....all these jobs. Crikey. Retrieved January 12, 2014 from

www.crikey.com.au/2009/11/23/all-those-journalism-graduates-all-these-jobs/

Diekerhof, E. Teaching journalistic research skills in the digital age: between traditional routines and advanced tools. Journal of Applied Journalism \& Media Studies, 2(2), 231-244.

Elliott, R., \& Jankel-Elliott, N. (2003). Using ethnography in strategic consumer research. Qualitative Market Research: An International Journal, 6(4), 215-223. 
Gentzkow, M., Glaeser, E. L., \& Goldin, C. (2006). The rise of the Fourth Estate: how newspapers became informative and why it mattered. In E. L. Glaeser \& C. Goldin (eds.), Corruption and reform: lessons from America's economic history (pp. 187-230). University of Chicago Press.

Hewitt, A., \& Forte, A. (2006, November). Crossing boundaries: identity management and student/ faculty relationships on Facebook. Poster presented at the Computer Supported Cooperative Work Conference, Banff, Alberta.

Hirst, M., \& Treadwell, G. (2011). BLOGS BOTHER ME: Social media, journalism students and the curriculum. Journalism Practice, 5(4), 446-461.

Johnson, J. C., Avenarius, C., \& Weatherford, J. (2006). The active participant-observer: applying social role analysis to participant observation. Field Methods, 18(2), 111-134.

Johnson, K. A. (2011). The effect of Twitter posts on students' perceptions of instructor credi bility. Learning, Media and Technology, 36(1), 21-38.

Lariscy, R. W., Avery, E. J., Sweetser, K. D., \& Howes, P. (2009). An examination of the role of online social media in journalists' source mix. Public Relations Review, 35(3), 314-316.

Ludtke, M. (2009). Let's talk: journalism and social media. Nieman Reports, 3(4). 4.

Mazer, J. P., Murphy, R. E., \& Simonds, C. J. (2007). 'I'll see you on Facebook': The effects of computer-mediated teacher self-disclosure on student motivation, affective learning, and classroom climate. Communication Education, 56(1), 1-17.

Newman, N. (2009, September). The rise of social media and its impact on mainstream journalism. Reuters Institute for the Study of Journalism. Retrieved January 14, 2014 from https:// reutersinstitute.politics.ox.ac.uk/fileadmin/documents/Publications/The_rise_of_social_media_and_its_impact_on_mainstream_journalism.pdf

Nguyen, A. (2006). Journalism in the wake of participatory publishing. Australian Journalism Review, 28(1), 143-155.

O’Donnell, P. (1999). The other 66 per cent? Rethinking the labour market for journalism graduates. Australian Journalism Review, 21(1), 123-142.

Qualman, E. (2012). Socialnomics: how social media transforms the way we live and do business. John Wiley \& Sons.

Shih, G. (2013, April). Boston Marathon bombings: how Twitter and Reddit got it wrong. The Independent. Retrieved January 11, 2014 from www.independent.co.uk/news/world/americas/ boston-marathon-bombings-how-twitter-and-reddit-got-it-wrong-8581167.html

Stassen, W. (2010). Your news in 140 characters: exploring the role of social media in journalism. Global Media Journal: African Edition, 4(1), 1-16.

Nasya Bahfen is a senior lecturer in the School of Media Film and Journalism, Monash University, Melbourne.

nasya.bahfen@gmail.com

Alex Wake is a lecturer in the School of Media and Communication, RMIT, Melbourne. alex.wake@rmit.edu.au

184 PACIFIC JOURNALISM REVIEW 21(1) 2015 